\title{
La circulación monetaria alto-imperial en el norte de la Mauretania Tingitana
}

\author{
The high-imperial monetary circulation in the north \\ of the Mauretania Tingitana \\ EnRique Gozalbes Cravioto*
}

\begin{abstract}
RESUMEN
ABSTRACT

En el presente trabajo se exponen y se analizan los datos disponibles sobre la In the present work they are exposed and the available information analyzes on the monetary circulation of Roman epoch in the North of the province of Mauritania Tingitana (current Morocco). The coins offer a testimony of the historical evolution of this country.

PALABRAS CLAVE: numismática, Imperio Romano, Marruecos, circulación monetaria.

KEYWORDS:

Numismatics, Roman Empire, empire, Morocco, monetary circulation.
\end{abstract}

\section{INTRODUCCIÓN}

Son bastante escasos los estudios realizados sobre la circulación monetaria de época alto-imperial en la provincia romana de la Mauretania Tingitana1. La mayor parte de las investigaciones realizadas sobre numismática antigua, al igual que se produce en el caso de las Hispaniae, han centrado su atención en el periodo anterior a la desaparición de las cecas locales en época del emperador Claudio².

* Universidad de Castilla-La Mancha. Avda. de los Alfares 44. 16002 Cuenca.

enrique.gozalbes@uclm.es

1 El presente trabajo es continuación de otro dedicado a «Nuevas series numismáticas antiguas de la Mauretania occidental», Nvmisma (251, 2007, pp. 39-56). No son abundantes los estudios sobre el conjunto del Norte de África. Vid. Salama, P.: «Huit siècles de circulation monétaire sur les sites cotiers de Maurétanie centrale et orientale (III siècle av. J. C.- V siècle ap. J. C. ", II Simposium Munismático de Barcelona, Barcelona, 1979, pp. 109-146.

2 Gozalbes, E.: «Novedades de numismática de la Mauretania occidental», Antiquités Africaines, 34 , 1998, pp.21-30 ; Callegarin, L. y El Harrif, F. Z.: «Ateliers et échanges monétaires dans le circuit du dé- 
También en el África occidental se aplicó una medida general del Imperio, de forma que las cecas locales mauritanas, Lixus y Semesh, así como las de las colonias romanas, en especial lulia Tingi, dejaron de emitir después de la conquista romana realizada en los inicios del imperio de Claudio ${ }^{3}$.

El trabajo general efectuado hace ya bastantes años sobre Hispania, reflejaba que en todo el periodo de las dinastías Julio-Claudia, de los Flavios y de los Antoninos, se documentaba una gran estabilidad en la circulación monetaria. El mayor número de las monedas aparecidas de la época de los Antoninos debía contrastarse con la duración mucho más extendida de esta dinastía, de forma que trasladados los datos a «número de monedas por año» existía un notable equilibrio ${ }^{4}$. Pese a todo, los autores no dejaban de señalar en los hallazgos hispanos que se documentaba cierta mayor proporción de monedas de Adriano, y una menor de Marco Aurelio-Cómodo ${ }^{5}$, aspecto que veremos documentado también en el Norte de la Tingitana.

En cualquier caso, todo estudio sobre circulación monetaria debe incluir alguna consideración de carácter metodológico. Como idea general, el mayor volumen de una masa de monedas atestiguada indica una mayor inmersión de una población en los mecanismos de la economía monetaria. Esta mayor circulación puede también, a grandes rasgos, considerarse un síntoma de prosperidad económica. Ahora bien, no es menos cierto que estas observaciones generales merecen notables matizaciones en los aspectos de detalle.

Desde hace bastantes años un elemento nombrado como el «número de monedas por año» recuperadas se ha planteado como un indicio significativo ${ }^{6}$, puesto que las cifras absolutas deben reducirse al terreno de lo relativo. Es cierto que estos datos ofrecen algunas direcciones de interpretación histórica, pero las mismas no son muy seguras. Deben tenerse en cuenta aspectos tales como el influjo

troit », en García Bellido, M. P. y Callegarin, L.: Los cartagineses y la monetización del Mediterráneo occidental, Madrid, 2000, pp. 23-42. Vid. ejemplos de actualización en el estudio de cecas locales, Fernández Uriel, P.: «La moneda de Rusaddir. Una hipótesis de trabajo», Gerión, 22, 2004, pp. 147-167; Gozalbes, E.: «La ceca mauritana de Tamuda y su identificación por Manuel Gómez Moreno», XIII Congreso Nacional de Numismática (Cádiz, 2007), en prensa.

3 Mazard, J.: Corpvs Nvmmorvm Nvmidiae Mauretaniaeque, Paris, 1955; Jenkins, G. K.: Sylloge Nummorum Graecorum. North Africa, Syrtica, Mauritania. The Royal Colection of coins and medals DaNISH nacional Museum, Copenhague, 1969; Burnett, A., Amandry, M. y Ripollés, P. P.: Roman Provincial Coinage. I. Fron the death of Caesar to the death of Vitellius, I, Paris, 1998; Amandry, A.; «Tingi», Mélanges de numismatique offerts à Pierre Bastien, Paris, 1987, pp. 1-14; Rhorfi, A.: «La contribution de la numismatique à la connaissance de la date de la foundation coloniale de Tingi', L'Africa Romana. XIV Convegno di Studio, Roma, 2000, pp. 2147-2162.

4 Bost, J. P., Campo, M. y Guart, J. M.: «La circulación monetaria en Hispania durante el periodo romano-imperial: problemática y conclusiones generales», I/ Simposium Numismático de Barcelona, Barcelona, 1980, pp. 174-183.

5 Aunque sin utilizar expresamente la documentación numismática, Sánchez León, M. L.: Economía de la Hispania meridional durante la dinastía de los Antoninos, Salamanca, 1978, concluía que la economía hispana alcanzó el cenit hacia el 170, entrando a partir de ese momento en declive. Vid. también el volumen Cité et communauté civique en Hispania, Madrid, 1993.

6 «La circulación monetaria en Hispania, Narbonense y Norte de África», I Simposium Numismático de Barcelona, Barcelona, 1979, pp. 13-16. 
de la casualidad en los hallazgos, el diferente carácter de los centros estudiados, y también otras consideraciones que se han planteado en ocasiones, tales como el mantenimiento residual de las monedas durante mucho tiempo ${ }^{7}$, cuestión apuntada pero acerca de la que no se han realizado suficientes investigaciones, o la necesidad de distinción en el valor de las monedas, si bien en el caso de la Tingitana la inmensa mayoría de las piezas son de bajo valor. Los procesos de inflación también pueden influir, así como es evidente que los fenómenos referidos a una vuelta al trueque que hacía, o podía hacer innecesaria la moneda en algunos momentos.

\section{ESTUDIOS SOBRE LA MAURETANIA TINGITANA}

Respecto a la provincia romana de la Mauretania Tingitana disponemos en el momento actual de algunos datos que, de forma en general muy poco sistémica, han sido considerados en algunas ocasiones en relación con la Historia de la provincia. De hecho, dos aportaciones importantes utilizaron la numismática para la reconstrucción histórica de momentos concretos de la provincia romana. La primera de ellas fue la de Jerôme Carcopino, quien estableció su conclusión utilizando los hallazgos de monedas romanas en Volúbilis y en Banasa. A partir de un alto número de piezas en la estadística, Carcopino detectaba que las series romanas en la práctica tenían una paralización en la época del emperador Probo; por el contrario, las monedas del siglo iv eran escasísimas, concretadas tan sólo en algunas piezas de Constantino. A la luz de los datos de la numismática, Carcopino concluía que en época de Diocleciano los romanos debieron abandonar una parte del país, efectuando un repliegue de sus posiciones hacia las zonas más septentrionales ${ }^{8}$.

Algunos años más tarde también utilizó la numismática el investigador español Miguel Tarradell, en este caso para documentar en Marruecos la crisis del siglo III. Los datos en este caso tienen quizás más valor cualitativo que cuantitativo, y serían muy influyentes en la historiografía. Por ejemplo, sobre las excavaciones de Lixus destaca tan sólo la aparición de algunas piezas de Caracalla, de Alejandro Severo, de Gordiano III, de Galieno y de la esposa de este último, si bien en relación con lo que el autor detectaba como destrucciones en las aristocráticas casas de Helios y de Marte y Rea. Y sobre todo, Tarradell aportaba un tesorillo de las rui-

\footnotetext{
7 Abascal, J. M.: «Hallazgos arqueológicos y circulación monetaria. Disfunciones metodológicas en el estudio de la Hispania romana», Actas del IX Congreso Nacional de Numismática, Elche, 1994, pp. 143-158.

8 Carcopino, J.: Le Maroc Antique, Paris, 1943, p. 248. La tesis del repliegue romano ha sido puesta en discusión en diversas ocasiones. No obstante, más allá de las valoraciones de este hecho, es poco cuestionable que las características de la civilización romana, entre ellas la utilización de la moneda para los intercambios, se vienen abajo aproximadamente a partir del año 285 , mientras los centros del Norte del territorio viven un nuevo esplendor. Por el contrario, estas contadas monedas, insignificantes en el conjunto, han sido utilizadas para poner en duda de forma poco verosímil la realidad del repliegue romano sobre el Norte del país, como en el caso de Villaverde, N.: Tingitana en la Antigüedad Tardía (siglos III-VII), Madrid, 2001.
} 
nas de Suiar (valle del Jarrub), descubierto en una campaña de excavación por él realizada, y que se componía de tres piezas de Adriano, una de Marco Aurelio, de Cómodo, seis de Alejandro Severo, una de Maximino I, una de Máximo y una de Gordiano III ${ }^{9}$.

Los resultados de las excavaciones efectuadas por los investigadores franceses, en especial Raymond Thouvenot, en Volúbilis, Banasa y Thamusida, fueron inicialmente publicados por Jean Marion. Este breve artículo del año 1960 ya aportaba datos importantes debido a la gran cantidad de monedas entonces conocidas ${ }^{10}$. Algunos años más tarde, este mismo autor completaba los datos con los nuevos descubrimientos, recogiendo una estadística más completa de la circulación monetaria ${ }^{11}$. Este importante artículo es el que hasta el momento ha servido como elemento de comparación para estudiar el caso de la Tingitana.

No obstante, pese a la importancia de estas series numismáticas, debe indicarse que las mismas no responden a la realidad de la totalidad del territorio. En el análisis de Marion están ausentes los centros de la zona septentrional del país, cuyos datos en lo posible deben también de utilizarse y, en parte, tienen gran interés para Hispania por su mayor cercanía y paralelismos con la misma. En este sentido, en 1987 desarrollamos un trabajo en el que integramos la documentación numismática, en la cual incluimos algunos datos de la región septentrional ${ }^{12}$. El hecho de que esta parte no fuera incluida en el amplio extracto que más tarde se publicó, con cierta actualización ${ }^{13}$, nos motiva ahora para volver sobre esta cuestión con datos más actualizados.

\section{TINGI (TÁNGER)}

Los hallazgos numismáticos han sido constantes en Tánger y su campo (Fahs), con los que en el siglo xx se han formado diversas colecciones que han salido del país sin estudio. Ya en el siglo XIX en la urbe tangerina se compraban muchas de las monedas allí aparecidas. No era tampoco novedad, en la plaza de Tánger ocupada por los ingleses en el siglo XVII los hallazgos de monedas por miles, vendidas a curiosos y coleccionistas; según un informe de la época, «los sol-

9 Tarradell, M.: »La crisis del siglo III de J. C. en Marruecos», Tamuda, 3, 1955, pp. 75-105. Estos temas fueron después objeto de la Tesis Doctoral de El Yousi, La crisis del siglo III y sus efectos sobre la circulación monetaria en la Mauritania Tingitana del Norte, dirigida por el profesor Pedro Voltes Bou, aunque con fuerte asesoramiento del profesor Miguel Tarradell Mateu (que formó parte del Tribunal), y se presentó en la Facultad de Ciencias Económicas y Empresariales de la Universidad de Barcelona 449-458.

10 Marion, J.: «Les séries monétaires de Tingitane », Bulletin d Archéologie Marocaine, 4, 1960, pp.

11 Marion, J.: « Note sur la contribution de la numismatique à la connaissance de la Maurétanie Tingitane », Antiquités Africaines, 1, 1967, pp. 97-117.

12 Gozalbes, E.: Economía de la Mauritania Tingitana (siglos I a.C.-Il d.C.), Tesis Doctoral (publicada en microfichas), Universidad de Granada, 187 (Tesis realizada bajo la dirección de Mauricio Pastor Muñoz). Capítulo XII, pp. 961-988.

13 Gozalbes, E.: Economía de Mauritania Tingitana, Ceuta, 1997. 
dados quando les falta el dinero se dan luego a buscar medallas y hallan con ellas el dinero que les faltava ${ }^{14}$. Este mismo informe señala que reconocía monedas de «todos los emperadores romanos", aunque eran particularmente numerosas las de Antonino Pio y las de Rómulo y Remo con la loba, piezas estas últimas del siglo $\mathrm{IV}^{15}$.

No obstante, estos datos son difíciles de integrar en un estudio sobre la circulación monetaria. La relación de las monedas descubiertas en Tánger en el siglo xx fue publicada, aunque no de forma detallada sino en un gráfico, por parte de Michel Ponsich ${ }^{16}$. Aunque el autor no lo indicara de forma expresa, dichas monedas corresponden no sólo a los hallazgos en la ciudad antigua sino en su región dependiente, que fue objeto de una intensa ocupación en época romana. Las principales conclusiones que se derivan de los datos son las siguientes:

1. Escasa presencia de las monedas del siglo I, de los momentos posteriores a Claudio, en la circulación monetaria. Es cierto que el número de monedas experimenta un cierto aumento en época de este emperador, pero disminuyen después de una forma muy notable con Nerón y el inicio de los Flavios.

2. Importante aumento de la circulación monetaria en la primera mitad del siglo II, bajo los emperadores Trajano y Adriano. Después este alto número de monedas «por año» halladas, disminuye algo a mediados del siglo con el emperador Antonino Pio.

3. En la segunda mitad del siglo II se produce esta drástica disminución de la circulación monetaria de una forma creciente. De esta forma, todavía cierto número de monedas de Marco Aurelio disminuye con el carácter meramente residual de la presencia de numismas de Cómodo, Septimio Severo o incluso Caracalla.

4. En el siglo III se evidencian tres alzas en la documentación de la circulación monetaria, en concreto bajo Alejandro Severo, Gordiano III y Galieno, después de los cuales la circulación monetaria aparece bastante reducida.

5. El siglo IV aparece en Tingi bastante mejor representado de lo que podría suponerse en una etapa caracterizada como de «crisis». En efecto, el número de monedas de Constantino es muy elevado, y después se producen también alzas bajo Constancio II y en las etapas finales del siglo IV.

Estos datos evidencian alzas y descensos en una ciudad que tuvo vida permanente a lo largo de todo el tiempo, por lo que no puede suponerse la existencia de reactivaciones motivadas por ocupaciones militares. Tingi pervivió como núcleo urbano desde siglos atrás, y la evolución de la circulación monetaria, más allá de

14 Informe de un espía español de 1674 manuscrito en la Biblioteca Nacional de Madrid, publicado por La Veronne, Ch. de: Tánger sous Poccupation anglaise d après une description anonyme de 1674, Paris, 1972, p. 140.

15 La Veronne, Ch. de, p. 141. Las acuñaciones que refiere son indudablemente las realizadas entre los años 324 y 330.

16 Ponsich, M.: Recherches archéologiques à Tánger et das sa région, Paris, 1970, p. 292. 
matizaciones metodológicas, ofrece datos acerca de la evolución de la economía romana en esta localidad. En el conjunto de los datos destaca la fuerte inclusión de la moneda imperial bajo Claudio, las alzas de Trajano-Adriano, e intermitentes a partir de Alejandro Severo en el siglo III, las fuertes alzas del siglo IV, así como la continuidad del uso de la moneda hasta las primeras décadas del siglo $\mathrm{V}$.

\section{TAMUDA (TETUÁN)}

Si Tingi evidencia la documentación en un centro urbano de la Tingitana septentrional, el caso poco utilizado de Tamuda (Tetuán) documenta un ejemplo de ocupación militar. La antigua ciudad mauritana, destruida en la guerra de conquista romana, fue sustituida en época romana por un castellum de forma cuadrada, de unos 95 metros aproximadamente de lado, con numerosas viviendas dispersas por los alrededores. Ya desde el descubrimiento de las ruinas de la ciudad, en el año 1921, se evidenciaron los numerosos hallazgos de monedas. Poco más se sabe acerca de los datos de estos primeros hallazgos, tan sólo (por un informe de Gómez Moreno) que las monedas romanas únicamente comenzaban a atestiguarse en época de Adriano.

Tampoco se dispone de los datos de las monedas aparecidas en las excavaciones realizadas por Miguel Tarradell entre 1948 y 1958. En sus breves aportaciones sobre las mismas nunca ofreció una relación de las monedas de época altoimperial. Por el contrario, sí disponemos de los datos del estado del monetario de Tamuda en el Museo Arqueológico de Tetuán en el año 1948, producto de los descubrimientos realizados en las excavaciones de Pelayo Quintero Atauri (19401945) y César Morán Bardón (1946). En efecto, el estudio realizado entonces por Felipe Mateu y Llopis ofreció varios centenares de piezas. De las mismas, del periodo mauritano, existen bastantes errores en la identificación de las cecas locales, y acerca de las mismas ya realizamos un trabajo de reinterpretación en su momento; por el contrario, a las series numismáticas alto-imperiales, de más fácil identificación, no se les ha prestado atención ${ }^{17}$.

La serie numismática de Tamuda en época romana representa la evolución de la ocupación en un establecimiento militar. A partir de la misma división cronológica que hemos considerado en Tánger podemos destacar estos datos:

1. El siglo I es un momento de escasa ocupación en Tamuda. No obstante, con cifras modestas, observamos dos alzas bajo Claudio y Vespasiano. Estos datos reflejan una duda, planteada en la posibilidad de que en esta época existie-

17 Los datos están recogidos por Tarradell, M.: «Estado actual de los conocimientos sobre Tamuda y resultados de la campaña de 1948», Archivo Español de Arqueología, 22, 1949, p. 92; Mateu y Llopis, F.: Monedas de Mauritania, Madrid, 1949, p. 46. Respecto a las excavaciones realizadas en el castellum por parte de Tarradell no hay apenas referencias; Tarradell, M.: «Las excavaciones de Tamuda de 1949 a 1955», Tamuda, 4, 1956, p. 84: «respecto a las monedas hay un gran predominio de las series constantinianas, en especial los pequeños bronces». 
ra ya una ocupación militar. El hecho no es en absoluto seguro, aunque podría indicar una etapa con un castellum militar realizado con materiales más efímeros.

2. En la primera mitad del siglo II se produce inicialmente un alza bajo Trajano, pero un aumento muy considerable bajo Adriano. Este hecho confirma la hipótesis ya planteada por Gómez Moreno, y que también Tarradell detectó en las excavaciones de 1958: la construcción del castellum en fechas iniciales del siglo II. El número de monedas por año prácticamente se triplica.

3. En la segunda mitad del siglo ॥ se produce una disminución paulatina del número de monedas, con la excepción del periodo de Marco Aurelio, con muy baja cifra en los últimos años de la centuria y en los primeros de la siguiente.

4. En el siglo III disminuye en general el número de monedas en circulación, si bien con presencia de todos los emperadores, y con alzas en dos emperadores concretos: Galieno y Claudio II el Gótico.

5. De forma sorprendente, el máximo de la circulación monetaria en Tamuda se produce en el siglo Iv, de forma que el número de monedas es más elevado incluso que las de los siglos II y III conjuntamente. El máximo muy evidente es de época de Constantino, el emperador (con mucho) cuyas monedas están más presentes. Pero la segunda mitad del siglo IV está muy bien representado, con acuñaciones de Teodosio, y también la extensión hasta los inicios del siglo $v$ puesto que son muy numerosas las monedas de Honorio y, sobre todo, de Arcadio.

\section{ZILIL (DCHAR JDID)}

La comparación entre un centro urbano y otro militar refleja, con mucha claridad, una coincidencia bastante consistente en la circulación monetaria en el Norte de la Tingitana. Estos datos pueden contrastarse con los publicados en fechas más recientes de las excavaciones realizadas en Dchar Jdid (junto a Had el Garbía) a partir de 1979. Este importante campo de ruinas había sido erróneamente identicazo con Ad Mercuri, si bien los descubrimientos epigráficos han demostrado que se trataba en realidad de la colonia romana de Iulia Constantia Zilil. En todo caso, las excavaciones más antiguas, efectuadas por César L. Montalbán en 1939 y 1941, también dieron unos abundantes hallazgos numismáticos que han pasado desapercibidos.

En el estudio realizado por Felipe Mateu y Llopis acerca de estas últimas piezas, se indicaba el neto predominio de las acuñaciones alto-imperiales sobre las anteriores a la conquista romana. El autor indicaba la presencia de 382 monedas alto-imperiales, si bien no establece una relación de las mismas. Eso sí, indicaba el neto predominio de las acuñaciones de Constantino, por tanto del siglo IV. Fuera de lo anterior, destacaban algunas monedas del siglo $1 \mathrm{II}^{18}$. También en el Museo de Ceuta

18 Mateu y Llopis, F., p. 48. 
existe una cierta cantidad de numismas de esta procedencia, de los que la gran mayoría son de los siglos III y IV, en especial de Galieno y, sobre todo, de Constancio II y Constante ${ }^{19}$.

Por el contrario, la publicación efectuada sobre las excavaciones modernas ofrece una visión mucho más completa acerca de la circulación monetaria. Nuevamente se refleja que la mayor cantidad de monedas es de Constantino, a las que siguen también en fuerte proporción otros emperadores del siglo IV. A la luz de la publicación parece bastante claro el auge de la ciudad en el Bajo Imperio ${ }^{20}$. También a la luz de estos datos existe coincidencia con los anteriores: el número de monedas de época alto-imperial es mucho más elevado que el de épocas anteriores. La evolución de la circulación monetaria muestra estos datos en Zilil:

1. El siglo I está muy escasamente representado, con la excepción de las monedas de Claudio. Aparentemente con la conquista romana se introducen con cierta fuerza las monedas de este primer emperador, pero con los posteriores se produce una notable disminución. Destacamos en este caso, más evidente que en los casos anteriores, el bajo número de las monedas de los Flavios.

2. En la primera mitad del siglo II se produce un modesto aumento bajo Trajano, y un alza muy considerable bajo Adriano, uno de los emperadores mejor representados en los hallazgos numismáticos.

3. Desde mediados del siglo II, y en la segunda mitad de esta centuria, se produce una disminución muy considerable y paulatina del número de monedas, con un ligero alza bajo Marco Aurelio.

4. La recuperación de época de Alejandro Severo no está atestiguada en Zilil, por el contrario la primera mitad del siglo III aparece de escasísima circulación monetaria. Por el contrario, un aumento muy considerable de piezas está atestiguado en la época de Galieno y de Claudio II el Gótico.

5. Finalmente, el gran momento en la circulación monetaria se produce en el siglo IV, con tendencias similares a las de otros centros del Norte de la Tingitana.

\section{OTROS HALLAZGOS}

La numismática de época romana imperial en otros lugares es muchísimo menos completa. Por este hecho, los datos únicamente pueden ser tenidos en cuenta como una mera referencia. En el campamento militar de Tabernae, en LaIla Yilalia, las excavaciones de Montalbán en 1939 dieron a la luz medio centenar de monedas, de las que tan sólo 22 eran de época romana imperial. De acuerdo

19 Abad Varela, M.: « Ceuta y su entorno en el Estrecho: relaciones económicas durante la antigüedad a través de la numismática», Actas I Congreso Internacional El Estrecho de Gibraltar, I, Madrid, 1988, pp. 1003- 1016.

20 Depeyrot, G.: Zilil I. Étude du numéraire, Roma, 1979. 
con la revisión de esas monedas por parte de Mateu y Llopis ${ }^{21}$, las piezas se iniciaba con una acuñación de Trajano, otra de Adriano, cuatro de Marco Aurelio; una pieza de Cómodo, de Alejandro Severo, Gordiano III, Filipo el Árabe y Galieno. El siglo Iv tiene una notable representación de Constantino (con nueve piezas) y de Teodosio. Así pues, también en este caso, aparentemente la posible ocupación militar se inició con Trajano-Adriano, en este caso con fuerte presencia en época de Marco Aurelio, y con notable representación de las monedas en las tres décadas centrales del siglo III. También en este caso el siglo IV está bien representado.

En las excavaciones realizadas por Carlos Posac en Ceuta, entre 1956 y 1976, hay reflejados diversos hallazgos numismáticos que se unen a descubrimientos casuales de momentos anteriores ${ }^{22}$, a las que se suman las piezas descubiertas después en las excavaciones de la basílica paleocristiana. Entre las monedas hay una presencia importante de piezas de Claudio, nada menos que siete. Con alguna pieza están representados Nerón, Domiciano, Trajano (dos), Adriano, Cómodo (dos), Alejandro Severo (dos),Maximino, Gordiano III, Treboniano, Diocleciano, Constancio II, Magnencio, Graciano, Teodosio (dos). Estos datos reflejan, si bien de forma modesta, la continuidad en la presencia romana en la ciudad desde el momento de la conquista, así como la importante presencia de los siglos III y IV ${ }^{23}$.

Bien poco se conoce de la numismática de Lixus, ya que los arqueólogos que trabajaron en la misma, Montalbán en los años veinte, Tarradell al final de lo cuarenta y en los cincuenta, o Ponsich en los sesenta, nunca publicaron los hallazgos de monedas, más allá de referencias muy generales. Respecto a las excavaciones más primitivas, en el monetario del Museo Arqueológico de Tetuán, Mateu y Llopis ofrece los datos de una forma muy genérica. Sobre la serie numismática se limita a indicar que «Lixus tuvo un evidente florecimiento durante los siglos II, III y IV, comprobado por las abundantes piezas numismáticas romanas de dichas centurias, particularmente de la última» ${ }^{24}$. El autor destacaba el florecimiento de la época de Constantino como momento de máximo esplendor, indudablemente por el predominio de numismas de este emperador.

Datos muy fragmentarios se tienen acerca de los hallazgos de monedas en la fábrica de salazones de pescado de Alcazarseguer, en plena costa del estrecho. Dado que esas monedas se hallaban en el Museo de Tetuán en 1948, cuando las estudió Mateu y Llopis, dichos datos corresponden con las aparecidas en el año

21 Mateu y Llopis, F., p. 50.

22 Posac Mon, C.: La Historia de Ceuta a través de la numismática, Ceuta, 1989. En la publicación anterior de monedas en colecciones particulares, «Monedas romanas imperiales halladas en Ceuta», Tamuda, 6, 1958, pp. 309-315, se recogían piezas de Claudio, Nerón, Domiciano, Trajano (dos), Antonino Pío, Cómodo, Máximo, Alejandro Severo, Gordiano III, Galieno, Galerio, Constantino (dos), Crispo, ceca de Constantinopla, Constantino II, Teodosio (dos) y Arcadio.

${ }^{23}$ Debe tenerse en cuenta la importancia relativa de las monedas halladas en la basílica paleocristiana y su entorno; Abad Varela, M.: «Estudio de los hallazgos numismáticos romanos en la basílica paleocristiana y Mirador II (Ceuta)», Actas II Congreso Internacional El Estrecho de Gibraltar, II, Madrid, 1995, pp. 563-580; Fernández Sotelo, E. A.: Basílica y necrópolis paleocristianas de Ceuta, Ceuta, 2000, pp. 145-146.

24 Mateu y Llopis, F., p. 30. 
1943 y que refiere Pelayo Quintero ${ }^{25}$. En el trabajo de Mateu y Llopis, no obstante, se cita un moneda más (veintitrés) aparecida en Alcazarseguer ${ }^{26}$ : Graciano (siete), Teodosio (once), Máximo, Arcadio (tres), Valentiniano III. Aparentemente la explotación de la pesca en esta localidad continuó hasta iniciados el siglo v.

Finalmente, también se señala la aparición de un tesorillo de monedas romanas en el Rif, en concreto en Annual. Este depósito estaba formado por un total de 35 sestercios, pertenecientes a Alejandro Severo, Maximino y Gordiano III27. La aparición de este tesorillo en una zona que, por lo general, se considera que no tuvo ocupación romana continuada, plantea la posibilidad de una presencia temporal.

\section{ANÁLISIS DE LOS DATOS}

Las series numismáticas del Norte de la Mauretania Tingitana, sin ser numerosas, ofrecen datos suficientes para realizar una comparación con las conocidas, y utilizadas por la historiografía respecto a la zona central y meridional de la provincia. En lo que se refiere a los tesorillos, el hallado en el campamento militar de Suiar (cuenca del Jarrub) muestra la perduración de las monedas durante mucho tiempo, pues en un ocultamiento de época de Gordiano III, había nada menos que tres monedas de Adriano, por tanto acuñadas más de un siglo atrás. En los tesoros monetales de Banasa y de Volúbilis detectamos un ámbito cronológico de circulación muchísimo más reducido, si bien en alguno de ellos aparecen incluso piezas anteriores a la conquista romana ${ }^{28}$. Debe tenerse en cuenta que en la necrópolis de Sala (Rabat), en tumbas datadas en época de los Flavios, aparecen como ofrendas monedas de acuñación gaditana, de más de un siglo atrás ${ }^{29}$.

En Banasa los siete tesorillos conocidos ocupan un ámbito cronológico bastante reducido, entre el 247 y el 279 , y se relacionan con las evidencias de la crisis del siglo III, expuestas en su día por Tarradell, en relación con el Norte de la provincia. Esta extensión de los ocultamientos induce a pensar no tanto en un momento concreto de invasión, la incursión de francos y alamanes como interpretó Tarradell, sino en un periodo bastante prolongado de inestabilidad. En este sentido, la utilización de los datos mantiene sus limitaciones, si bien el caso de Banasa

25 Quintero, P. y Giménez, C.: Excavaciones en Tamuda. Memoria resumen de las practicadas en 1943, Tetuán, 1944, p. 25: «estas monedas suman el número de 22 y son de bronce de pequeño módulo y cuya acuñación puede basarse entre los siglos III y IV ».

26 Mateu y Llopis, F., p. 30.

27 Barrio, C.: « La numismática y Melilla », Aldaba, 30, 1998, pp. 217-223.

28 Marion, J.: «Les trésors monétaires de Volúbilis et de Banasa», Antiquités Africaines, 12, 1978, pp. 179-215, y también con anterioridad de este mismo autor « Les dépôts monétaires du quartier du Macellum à Banasa », Bulletin d Archéologie Marocaine, 5, 1964, pp. 201-233. Destaca la similitud en el siglo III entre la circulación monetaria de Britania y de Tingitana.

${ }_{29}$ Boube, J.: Les nécropoles de Sala, Paris, 1999. También Bost, J. P., Campo, M. y Gurt, J. M., «La circulación monetaria», p. 176 señalaban que probablemente se mantuvo la circulación residual de las cecas locales. 
parece reflejar esa inestabilidad que no es tan claramente perceptible en otros lugares $^{30}$. El tesorillo al parecer hallado en Annual también refleja este mismo momento de inseguridad, además más allá de la zona de ocupación permanente.

Por último, en el manuscrito del siglo XVII que ya hemos referido, se documenta el descubrimiento de un tesorillo en la costa al Sur de Arcila: «pocos días ha que haziendo aguada una balandra francesa más allá de Arzilla, hallaron una urna con cantidad de medallas. El patrón de la embarcación truxo alguna cantidad de ellas que repartió en Tánger. A mi me dio quatro, y todas parecen de un género, esto es de los emperadores Theodosio, Honorio y Arcadio ${ }^{31}$. Corresponden, por tanto, a emisiones realizadas entre el 402 y el 408.

En lo que respecta a la evolución de la circulación monetaria debemos tener en cuenta los siguientes datos expresados de forma estadística en relación con el «número de monedas por año» en las colecciones numismáticas del Norte de la provincia.

\begin{tabular}{|c|c|c|c|}
\hline Años de extensión & TINGI & TAMUDA & ZILIL \\
\hline 40 al 69 & $0 ’ 5$ & $0 ’ 2$ & $0 ’ 9$ \\
\hline 69 al 96 & $0 ’ 2$ & $0 ’ 3$ & $0 ’ 3$ \\
\hline 96 al 138 & 1,0 & $0 ’ 7$ & $1 ' 5$ \\
\hline 138 al 180 & $0 ’ 7$ & $0 ’ 9$ & $0 ’ 7$ \\
\hline 180 al 211 & $0 ’ 2$ & $0 ’ 2$ & 0,1 \\
\hline 211 al 235 & $0 ’ 9$ & 0 '4 & 0,1 \\
\hline 235 al 285 & $1 ' 2$ & $1 ' 3$ & 14 \\
\hline
\end{tabular}

En general, los datos tienen bastantes coincidencias, como son el momento de máximo (235 al 285), y las dos etapas de mínimos (69 al 96 y 180 al 211). En lo que se refiere a los tres centro meridionales, Volúbilis, Thamusida y Banasa, estas series numismáticas comparten el momento de máximo, pero en los que respecta a los mínimos hay coincidencia con Thamusida, y en proporciones menores con Banasa, pero no así con Volúbilis. En todos los casos se manifiesta un considerable aumento de la circulación monetaria a partir de comienzos del siglo II, lo que evidencia desde ese momento la expansión de una economía monetaria.

30 En relación con el caso hispano vid. la discusión en Cepas Palanca, A.: «Uso de la numismática como documento histórico: las invasiones del siglo III», en García Bellido, M. P. y Sobral, R. M. (Eds.): La moneda hispánica. Ciudad y territorio, Madrid, 1995, pp. 361-368. Vid. con anterioridad, Sagredo, L.: «Las invasiones del siglo III de C. en Hispania a la luz de los tesorillos monetales», Hispania Antiqva, 11-12, 1981-1985, pp. 89-104.

31 La Veronne, Ch. de, p. 142 
La evolución general de la circulación monetaria en la zona septentrional de la provincia puede reconstruirse de la siguiente forma:

1. Las monedas de Claudio están muy bien representadas en las series numismáticas de la provincia. La incorporación del país africano, así como la eliminación definitiva de acuñaciones locales, condujo a la necesidad de introducir de forma más abundante las acuñaciones imperiales ${ }^{32}$. El número de monedas es muy alto en todos los casos, tanto en lo que se refiere a una ciudad importante, caso de Tingi, como a un puerto de mar y centro pesquero como es el caso de Septem (Ceuta), incluso con matices en un establecimiento militar como es el de Tamuda ${ }^{33}$.

Este hecho es plenamente coherente con lo documentado en las ciudades más meridionales, como Banasa, Thamusida y Volúbilis. Y dada la ausencia, o extrema escasez de las monedas de Nerón, más allá de la damnatio memoriae que condujera a la retirada posterior de sus acuñaciones, hecho por lo demás común en España, parece indudable que las piezas de Claudio estuvieron en circulación mucho tiempo después de su muerte.

2. El periodo de los emperadores Flavios tiene una escasísima presencia en la ciudad de Tingi (0'2 monedas por año). De igual forma, esta baja cifra (0'29 por año) también está presente en el establecimiento militar de Tamuda. Si observamos otras series numismáticas, detallada o someramente publicadas, los datos se confirman. En Zilil la cifra de monedas de los Flavios (nueve) es ridícula frente a, por ejemplo, las 23 piezas de Claudio o las 37 de Adriano. La ausencia en Tabernae o en Lixus también es poco previsible, al contrario que en Alcazarseguer, puesto que esta factoría pesquera debió tener su origen en momentos posteriores. ¿A qué se debe esta atonía en la circulación monetaria bajo los Flavios? La respuesta es problemática.

Así pues, es muy evidente con los datos actuales, que la circulación monetaria fue escasa en el Norte de la provincia, tal y como se manifiesta en los centros civiles y en los militares. Este hecho contrasta con la situación en las ciudades del resto de la provincia romana, como se atestigua en las cifras recogidas por Marion. En Volúbilis hay documentadas numerosas monedas de Domiciano y de Vespasiano, hasta el punto de suponer 7'2 monedas por año bajo la dinastía (el doble que en el periodo anterior). En Banasa son muy numerosas las piezas de estos dos emperadores (4'5 por año), si bien son inferiores a las de las otras etapas. Finalmente, lo mismo ocurre en Thamusida (3'2 monedas por año), una cifra muy similar a la de la etapa anterior.

Los datos pueden también compararse con los de Hispania, para la que se poseen algunas series relativamente completas. Nos interesan en especial dos ciu-

32 Ripollés, P. P.: «Circulación monetaria en Hispania durante el periodo republicano y el inicio de la dinastía Julio-Claudia», Actas VIII Congreso Nacional de Numismática, Madrid, 1994, pp. 146-147.

${ }_{33}$ Villaverde, N., p.230 apunta a la posibilidad de que la instalación militar más primitiva fuera de época de Claudio. 
dades muy cercanas de la costa hispana. Así en Carteia el número de monedas por año de la época de los Flavios corresponde a menos de la mitad que el periodo anterior. Más clarificador aún es el caso de Baelo Claudia: 10 monedas de los Flavios frente a 54 de Claudio y 12 de Nerón ${ }^{34}$. A juzgar por los datos, en época de los emperadores Flavios existió un mayor volumen relativo de circulación monetaria en los centros meridionales de la Tingitana, mientras los septentrionales aparecen con cifras más bajas, al igual que se documenta en los puertos hispanos más cercanos $^{35}$.

Más difícil parece el encontrar una explicación a estas disidencias informativas. La época de los Flavios aparece en Hispania con una circulación monetaria mucho mayor en Italica (Bética), en Conimbriga (Lusitania), si bien por lo general también por debajo de la época de Claudio. No obstante, en la Tarraconense también aparece en cifras que son mucho más modestas ${ }^{36}$. Para el caso de la Tingitana las cifras modestas podrían reflejar una mayor atención hacia las zonas más alejadas del Estrecho, si bien son datos problemáticos. La hipótesis que supone que el establecimiento definitivo del dispositivo militar de la Tingitana, a partir de las conocidas cohortes y alas auxiliares, fue realizado por los Flavios, encuentra aquí cierta limitación ${ }^{37}$.

3. El comienzo de los Antoninos. Ya Tarradell indicó que la romanización de Marruecos experimentó un notable crecimiento con Trajano ${ }^{38}$. Los datos recogidos por Marion tampoco dejan lugar a dudas, si bien ese incremento se hizo muchísimo mayor en época de Adriano; así su estadística reflejaba que en Volúbilis las monedas de Trajano son 206, frente a 565 de Adriano, en Banasa son 113 frente a 348, y en Thamusida 82 frente a 208. Los datos indican un fuerte salto en la circulación monetaria en época de Trajano, pero el mismo se hace muchísimo mayor (bastante más de doble) bajo Adriano: 401 monedas del primero frente a $1121 \mathrm{del}$ segundo.

El análisis de las series numismáticas del Norte de la provincia confirma también estos datos, con algunos matices. Así en Tánger las monedas de Trajano son 17, y las de Adriano 21, en Tamuda las del primero son 8 frente a 22 de Adriano.

${ }^{34}$ Bost, J. P., Chaves, F., Depeyrot, G., Hiernard, J. y Richard, J. C.: Belo IV. Les monnaies, Madrid, 1987, pp. 59-64.

${ }_{35}$ Por el contrario, la proporción de monedas de los Flavios es bastante más alta en las tierras de Málaga; Mora Serrano, B.: «La circulación monetaria en los territorios malacitanos durante la antigüedad», en Wulff, F. y Cruz Andreotti, G. (Eds.): I/ Congreso de Historia Antigua de Málaga. Comercio y comerciantes en la Historia Antigua de Málaga, Málaga, 2001, p. 434.

${ }_{36}$ Vid. en general Arrizabalaga, I: Circulación monetaria en Hispania de Vespasiano a Adriano, Alicante, 1996.

${ }^{37}$ La tesis fue apuntada por nosotros a partir, sobre todo, de los diplomas militares, del número de las cohortes y alas de caballería; Gozalbes, E.: «El ejército romano de ocupación en Mauritania Tingitana en el siglo I’, Hispania Antiqva, 20, 1996, pp. 253-272. Vid. también Euzennat, M.: Le limes de Tingitane. La frontière méridionale, Paris, 1989. Debe tenerse en cuenta que también es de esta misma época la reorganización de la defensa de Hispania; Le Roux, P.: L'Armée romaine et Porganisation des provinces ibériques d Auguste a linvasion de 409, Paris, 1982.

${ }^{38}$ Tarradell, M.: «Acerca de las etapas de la romanización en Marruecos», Actas del III Congreso Arqueológico Nacional, Zaragoza, 1955, pp. 213-220. 
Mayor es todavía la diferencia en Zilil, 8 monedas de Trajano frente a 37 de Adriano. Sumando otros hallazgos menores, en el Norte de la provincia en época de Trajano se produce un salto en la circulación monetaria, pues hay atestiguadas 36 monedas, pero bajo Adriano la intensidad del cambio se refuerza pues han aparecido 85 monedas. Como puede observarse, la proporción es muy similar a la de las ciudades meridionales. Así pues, si en la época de los Flavios la zona septentrional mantenía unas líneas de una escasa circulación monetaria, como se documenta en puertos hispanos meridionales, bajo Trajano y Adriano las características se unifican en el conjunto de la Tingitana.

4. El desarrollo de los Antoninos ${ }^{39}$. En Tingi se produce una reducción de monedas documentadas en la etapa posterior a Adriano. De igual forma, en otro centro urbano cercano, Zilil, la reducción es bastante importante. No es el caso directamente de Tamuda, donde existe la presencia de un número importante de numismas de Antonino Pio y de Marco Aurelio (junto a las acuñaciones a nombre de sus respectivas esposas). También en otro establecimiento militar, el de Tabernae (si bien con datos más fragmentarios) esta disminución drástica no se produce. Estos datos apuntan a que en el Norte de la provincia las ciudades documentan una hipotética menor actividad, mientras por el contrario los centros militares viven una reactivación. Es muy posible que este hecho pueda ponerse en relación con el incremento de la importancia del estamento militar en la provincia, paralelo al problema de tumultos por parte de un sector no enteramente asimilado de la población indígena.

¿Qué ocurre en los restantes centros de la provincia? El estudio de Marion permite observar como en Volúbilis se vive una etapa de desarrollo, al menos es lo que se deduce de la circulación monetaria, en especial bajo Marco Aurelio; en Banasa se mantiene con ligero crecimiento el desarrollo del periodo anterior, sobre todo bajo Marco Aurelio; en Thamusida, por el contrario, se produce una disminución de la circulación monetaria. Estos datos, algo contradictorios, resultan también difíciles de encajar con los de Hispania: en Belo aumento bajo Antonino, severa disminución con Marco Aurelio, al igual que aparece documentado en Carteia.

5. El siglo III presenta una de las mayores problemáticas para el estudio de la provincia africana. En todos los aspectos parece representar un máximo, en sus primeras décadas, y una fuerte crisis transcurrida la mitad de ese siglo. Volúbilis experimenta un notable auge, como se manifiesta en la política constructiva ${ }^{40}$. Menores datos se disponen para otras ciudades, si bien en casos septentrionales como Tingi o Lixus no parece que se produjeran mejoras tan significativas del ornamento urbano. La circulación monetaria permite realizar una mayor aproximación a esta problemática. En resumen, los distintos casos de la Tingitana son los siguientes:

39 En relación con el caso de Hispania, Ripollés, P. P.: «La moneda romana imperial y su circulación en Hispania», Archivo Español de Arqueología, 185-186, 2002, pp. 273-290; Lledó Carmona, N.: El uso de la moneda en las ciudades romanas de Hispania en época imperial: el área mediterránea, Valencia, 2004.

40 Chatelain, L.: Le Maroc des romains, Paris, 1944. 
- Volúbilis. Aumento muy considerable de la circulación monetaria en el periodo 211-237, con un máximo en época de Alejandro Severo, y con posterioridad en época de Gordiano III.

- Banasa. Aumento muy considerable de la circulación monetaria en el periodo del 211-235, en especial bajo Alejandro Severo, aunque máximos se producirán más adelante bajo Gordiano III, Galieno y Claudio II.

- Thamusida. Aumento en el periodo 211-235, en especial en época de Alejandro Severo, aunque con máximos posteriores en época de Galieno y Claudio II.

- Tingi. Datos con alzas y bajas. Alza bajo Alejandro Severo, y más tarde con Gordiano y con Galieno.

- Zilil. Escasas monedas de la primera mitad del siglo III. Fuerte representación de Galieno y de Claudio II.

- Tamuda. El aumento se produce sobre todo bajo Galieno y, sobre todo, bajo Claudio II.

Los datos aquí recogidos indican la existencia de ciudades como Volúbilis, Tingi, Banasa y Thamusida en las que la etapa de Alejandro Severo se manifiesta por una considerable circulación monetaria. A juzgar por estos casos, abundantes, se trata de un momento de fuerte reactivación de la economía tingitana. El hecho también puede ponerse en relación con la reconstrucción de determinados campamentos militares, tales como el de Aïn Schkour en el limes meridional, o el de Tamuda en el septentrional. Este último caso siempre ha sido objeto de discusión. No obstante, en una memoria de excavaciones de Pelayo Quintero, en los años cuarenta, se refleja un dato precioso: la construcción de una de las puertas monumentales se relaciona con una moneda a flor de cuño del usurpador Pupieno, lo que data la reconstrucción y monumentalización del castellum en los inicios del gobierno de Gordiano III ${ }^{41}$.

Por el contrario, el caso de la ciudad de Zilil contrasta con lo señalado con anterioridad. Sin embargo, los datos son muy coincidentes en la pujanza de las acuñaciones de tres emperadores de la época de la tan renombrada crisis, Galieno, Gordiano III y, sobre todo, Claudio II el Gótico. Estos datos de la circulación monetaria plantean el problema de la realidad de la crisis del siglo III pues, al menos de una forma aparente, en vísperas del repliegue romano la vida en la provincia aparece particularmente activa. La decisión romana de abandonar una parte del país, entregado sin duda para su custodia al pueblo federado de los Baquates, debe ponerse mucho más en relación con la política general romana, y la búsqueda de una disminución en los gastos, que con necesidades imperiosas de inseguridades irresolubles en la provincia, tal y como interpretó Carcopino.

${ }^{41}$ La cuestión la hemos documentado y expuesto en Gozalbes, E.: «La frontera militar de Tamuda (Tetuán, Marruecos)», 20th Internacional Congreso of Roman Frontier Studies, Actas en prensa. 
El uso de la moneda en la Tingitana del siglo III escapa de forma muy acentuada de la situación tal y como aparece documentada en Hispania, en la que aparentemente se produce disminución respecto a la centuria anterior ${ }^{42}$

6. A juzgar por la circulación monetaria, el siglo iv se caracteriza por dos hechos complementarios: notable reactivación económica en el Norte de la provincia, así como alternancias en la situación ${ }^{43}$. Resulta muy difícil no ver en esta reactivación el resultado de un aumento de la población, por la posible concentración de los emigrados desde ciudades meridionales. Pero también este despliegue refleja que es insuficiente a todas luces la interpretación de la Tingitana bajo-imperial como un mero guardaespaldas defensivo de Hispania, a cuya administración se incorporó.

En todos los centros urbanos y militares se manifiesta la reactivación del denominado «renacimiento constantiniano». Una vez pasados los problemas del tránsito del siglo III al Iv, la nueva y reducida Tingitana, en torno a Tingi su capital, experimentó un desarrollo bien evidente. La gran cantidad de moneda, no olvidemos que se trata de pequeños bronces, puede reflejar fenómenos de inflación, pero también resulta indudable la plena imposición de un sistema de economía monetaria. Y la misma, y no el trueque natural, se impone durante todo el siglo IV, puesto que si en el segundo tercio se detecta en la circulación de monedas un nuevo decaimiento, sin duda porque mantienen su uso los numerosísimos numismas anteriores, una nueva reactivación se produce en la época del entorno de Teodosio.

7. La ocupación romana, a juzgar por la circulación monetaria, se extiende en el Norte del país a las dos primeras décadas del siglo v. El Imperio se resiste a perder el control de la Tingitana. La circulación de monedas en ciudades como Tingi o Zilil, o en una factoría de salazón de pescado como Alcazarseguer, manifiesta esa continuidad. Nos parece bastante más significativo el caso del establecimiento militar de Tamuda, en las que los numismas de Honorio y de Arcadio manifiestan una reactivación final de la ocupación ${ }^{44}$. Incluso en la última campaña de excavaciones, la limpieza sistemática realizada en 1963, aparecieron una moneda de bronce de Honorio, y dos monedas de oro de este mismo emperador ${ }^{45}$.

Así pues, los datos de la numismática reflejan un mantenimiento de la ocupación militar en Tamuda en el entorno del 415 al 423 . Se trata justamente del momento en el que el rey visigodo Walia, en esa época aliado de Roma en nombre de

42 Arias Ferrer, L.: La circulación monetaria en el Levante peninsular durante el siglo II d.C., Alicante, 2006; «Uso y circulación de la moneda durante el Alto Imperio en el Sureste peninsular», Nvmisma, 55, 2005, pp. 83-119.

43 Sobre el siglo IV en Hispania, Abad Varela, M.: «Circulación monetaria durante el Bajo Imperio Romano", Actas VIII Congreso Nacional de Arqueología, Madrid, 1994, pp. 149-166; San Vicente, J. I.: Circulación monetaria en Hispania durante el siglo IV d.C., Madrid, 1999.

44 La presencia de un número importante de monedas de estos emperadores ya está reflejada en 1922 en el informe de Manuel Gómez Moreno. En las excavaciones de 1940 a 1946 se documentan 14 monedas de Honorio y 27 de Arcadio; Tarradell, M. «Estado actual», p. 92.

45 Khatib, N.: «Chroniques», Bulletin d’Archéologie Marocaine, 5, 1964, pp. 376-378. 
la que actuaba en Hispania, intentó el paso del fretum Gaditanum, sufriendo entonces una terrible pérdida a causa de una tormenta marina. El paso de los visigodos, en las circunstancias del momento, tan sólo puede entenderse en el contexto de su alianza con Roma, que sin duda le había entregado como pueblo federado el Norte de la Tingitana para su establecimiento. La ocupación militar del Imperio llegó hasta muy poco después. Los visigodos ocuparían más tarde la Aquitania, en lugar de la Tingitana, y Roma perdió el control de su provincia africana más occidental. Y con esa pérdida del control, y la entrada directa en lo que Gautier llamó «siglos oscuros», desapareció la circulación de moneda imperial, que dejó de llegar incluso poco antes del paso de los vándalos en el año 429. 